\title{
A AGRESSIVIDADE INFANTIL EM SALA DE AULA E A INFLUÊNCIA DOS FATORES ESCOLARES
}

Rafaela Reginato Hosokawa, Andréia Cristiane Silva Wiezzel

Pedagogia, Departamento de Educação, Faculdade de Ciências e Tecnologia- UNESP. Órgão de fomento: CNPq. E-mail: rafaela reginato@hotmail.com

\section{RESUMO}

A agressividade infantil constitui tema de pesquisa atual e universal, com o qual pais e professores apresentam dificuldades para compreender e lidar. Com o intuito de investigar as possíveis causas do aparecimento da conduta agressiva em sala de aula, realizou-se um estudo bibliográfico da teoria Winnicottiana, a partir do qual refletiu-se sobre os possíveis fatores que podem colaborar para o surgimento desse tipo de manifestação. Dentre os fatores encontrados na investigação teórica, estão aqueles oriundos do contexto escolar, que serão apresentados e discutidos no presente artigo, visando refletir acerca das possibilidades de auxílio em relação à criança que apresenta agressividade.

Palavras-chave: Agressividade infantil; desenvolvimento emocional; Winnicott; fatores escolares; possibilidades de contribuição.

\section{INTRODUÇÃO E OBJETIVO}

O presente artigo se refere a um recorte de uma pesquisa de iniciação científica, que teve como objeto de estudo os fatores que podem levar à agressividade infantil em sala de aula. Para se compreender e analisar tais fatores, realizou-se um levantamento bibliográfico da teoria de Winnicott acerca do tema. Nessa investigação, observou-se os impactos dos fatores familiares e escolares na mobilização e manutenção da conduta agressiva, assim como de algumas ocorrências gerais no desenvolvimento emocional, que também influenciam na agressividade. Após a identificação de tais fatores, foi possível depreender formas de auxílio que a família e escola podem oferecer à criança agressiva. O mais interessante é que, ao contrário do que parece, as formas de atuação identificadas nesse estudo não extrapolam as habilidades e funções sociais de ambas, constituindo-se condições básicas para o desenvolvimento pleno da criança e para a sua capacidade de conviver em grupo.

Refletir e discutir acerca de tais questões é relevante, uma vez que é frequente a queixa de professores em relação à conduta agressiva de algumas crianças em sala de aula e, na maioria dos casos, a agressividade gera dificuldades de relacionamento que se configuram grandes desafios para estes profissionais, que, geralmente, não tiveram formação específica para compreender e lidar com questões dessa natureza. 
Acredita-se que, primeiramente, é fundamental que haja conhecimento sobre as raízes da agressividade para que, a partir da conscientização dos possíveis motivos que originam a conduta agressiva, sejam traçadas medidas preventivas bem como se realizem intervenções adequadas pelos professores e pais nos casos em que o problema já se faça presente.

Assim, este artigo tem como objetivo central refletir sobre os fatores escolares que podem levar ao desenvolvimento da agressividade em sala de aula, bem como as possibilidades de auxílio à criança que apresenta agressividade, a partir das contribuições teóricas de D. W. Winnicott, autor que investigou o desenvolvimento emocional infantil. Para abordar o tema proposto, inicialmente, serão tratados os aspectos escolares que podem mobilizar a conduta agressiva encontrados nas obras analisadas. Elencados esses fatores, discutiremos em que medida a escola pode contribuir para amenizar a conduta agressiva.

\section{METODOLOGIA}

Para atingir os objetivos propostos foram realizados, nesta pesquisa de natureza bibliográfica, levantamento e análise das obras de Winnicott.

A presente pesquisa se insere em uma abordagem qualitativa que, de acordo com o que apresentam Bogdan e Biklen (1982 apud LÜDKE; ANDRÉ 1986, p.13), “[...] envolve a obtenção de dados descritivos, obtidos no contato direto do pesquisador com a situação estudada, enfatiza mais o processo do que o produto e se preocupa em retratar a perspectiva dos participantes".

\section{RESULTADOS}

A teoria Winnicottiana considera a agressividade parte constitutiva do ser humano e elemento necessário para o transcorrer do processo evolutivo que, quando ocorre de modo saudável, culmina no desenvolvimento de características e capacidades indispensáveis para o bem-estar psíquico e para os relacionamentos interpessoais.

Entende-se que quando o desenvolvimento emocional é apoiado por um ambiente suficientemente bom, os impulsos destrutivos convertem-se em uma força valiosa, que constitui a base de atividades como o trabalho e o brincar, a partir da qual o desenvolvimento pessoal pode se enriquecer, sem que se perca a capacidade para se tornar agressivo nos momentos adequados. 
No caso da criança que apresenta agressividade, algo a tornou incapaz de administrar seu potencial agressivo no íntimo e convertê-lo em agressividade madura. $A$ análise bibliográfica mostrou que a conduta agressiva trata-se de um processo que envolve diversos fatores de ordem individual e social, não sendo possível identificar fator único como responsável. Nessa perspectiva, as manifestações agressivas no contexto escolar são compreendidas enquanto indícios de que algum fator ou fatores impediu o transcurso normal do desenvolvimento emocional.

A escola é um espaço de suma importância ao desenvolvimento da criança, que influencia diretamente na constituição do sujeito, podendo interferir tanto positiva como negativamente. Dessa forma, por meio dos conteúdos aqui abordados buscará se destacar de que maneira a escola pode estar cooperando para a mobilização e manutenção da agressividade infantil, pois compreender tais fatores pode ser uma forma de preveni-los.

Partindo do pressuposto da importância do ambiente para o processo de maturação do indivíduo na teoria winnicottiana, pode-se alegar que um ambiente hostil, no qual a criança se sinta excluída ou marginalizada, trará consequências negativas para esta, que poderão manifestar-se por meio de atos destrutivos.

A investigação evidenciou a influência do professor enquanto referência de comportamento para a criança. Um professor que adota uma postura autoritária, agressiva e utiliza mecanismos como o grito para colocar ordem na sala de aula, servirá de referência para a criança, que baseará seu comportamento no dele.

A rejeição dos colegas é outro fator que poderá originar a conduta agressiva e, muitas vezes, o professor pode ter influência nisso sem que perceba, ao referir-se de modo que denigra ou humilhe o aluno perante os demais, como é o caso da frequente frase: "Ainda bem que fulano faltou à aula hoje. Perceberam como hoje está melhor? Poderia ser todo dia assim!"

A expectativa que o professor tem em relação ao aluno também influi em seu desempenho escolar e comportamento. O aluno tende a se transformar naquilo que o professor espera dele. Comportamentos docentes como apontar o aluno tido como "impossível", alertando que quem for seu professor no ano seguinte terá problemas, gera uma expectativa negativa, que deve ser evitada.

Quando as condutas agressivas já se fazem presentes, a postura retaliativa ou vingativa do professor poderá reforçá-las, assim como a não compreensão de um sintoma 
agressivo enquanto pedido de ajuda e a não aceitação, por parte do professor e dos colegas, das tentativas de reparação feitas pela criança agressiva.

A falta de conhecimento teórico em relação aos aspectos emocionais dificulta a prática docente, pois o professor não terá um repertório a partir do qual compreenderá os conflitos infantis e as possibilidades de lidar com eles, podendo, por exemplo, não fornecer espaço para que a criança exerça sua capacidade de reparação com ele e com os colegas.

Como pode ser observado, grande parte dos fatores citados são oriundos de uma formação precária dos profissionais de educação no que diz respeito ao desenvolvimento emocional infantil.

Apesar de as manifestações agressivas se tratarem de algo complexo, que nem sempre pode ser auxiliado sem um apoio de um profissional especializado, acredita-se que as instituiç̧̃̃es que cuidam da formação da criança podem ajudá-las em certa medida.

\section{DISCUSSÃO}

Ao iniciar a discussão em relação às formas de ajuda que a escola pode fornecer à criança visando contribuir para a amenização da conduta agressiva, faz-se necessário postular algumas dificuldades intrínsecas ao ambiente escolar, para, posteriormente, discutir-se as possíveis formas de contribuição.

Conforme Winnicott (1982) a criança pequena ainda necessita, quando entra na escola, de cuidados muito próximos aos cuidados maternos e buscará se relacionar mais com o professor do que com as outras crianças. Quanto menor for a criança, mais ela estará em torno do professor, procurando reviver a relação com a mãe, no entanto, o professor não deverá ser um substituto da mãe, mas sim uma extensão dela. Gradualmente, a professora deixará de ser a figura central e a criança passará a se relacionar mais com os colegas.

A escola, que é um apoio, mas não uma alternativa para o lar da criança, pode fornecer oportunidade para uma profunda relação pessoal com outras pessoas que não os pais. Essas oportunidades apresentam-se na pessoa da professora e das outras crianças e no estabelecimento de uma tolerante, mas sólida, estrutura em que as experiências podem ser realizadas. (WINNICOTT, 1982, p.217)

À medida que a criança cresce essa figura do professor como extensão materna tende a desaparecer naturalmente e a escola adquire outro caráter, em que a aprendizagem se torna central e o professor começa a ser entendido como um mediador do conhecimento. $\mathrm{O}$ 
crescimento envolve ampliar as relações com o mundo externo e, concomitantemente, enriquecer o mundo interno através dessas experiências.

O problema é que essa concepção materna da escola nem sempre é superada. $\mathrm{Na}$ visão do autor, isso ocorre devido à realidade complexa do ambiente escolar, que recebe dois grupos de crianças, fora aquelas que se encontram em um grupo intermediário.

O primeiro grupo seria formado por aquelas crianças que tiveram experiências satisfatórias em seus lares, o que as tornou capazes de gerenciar, de maneira madura, os mais variados tipos de sentimentos. Tais crianças conseguem se beneficiar do ensino fornecido pela escola e contribuir com ele, pelo fato de estarem bem estruturadas internamente, graças à vivência em um círculo de amor, tolerância e confiança.

Ao contrário desse primeiro grupo, há, também, aquelas crianças cujos lares falharam e a escola constituirá um espaço que poderá oportunizar a elas a referência que deveriam ter tido em um período anterior. Essas crianças irão à escola tentando encontrar um ambiente estável e voltado para suas necessidades e a escola não deveria negar esse sentimento de segurança a elas.

Portanto, a escola precisa reconhecer que, para algumas crianças, esta não será um espaço, primordialmente, de aprendizagem, já que enquanto as dificuldades emocionais persistirem, essas crianças não conseguirão tirar muito proveito do ensino oferecido. O pedido de ajuda dessas crianças poderá se manifestar sob forma de conduta agressiva em sala de aula, que deveria ser entendida enquanto um sinal de esperança que elas ainda possuem de retomar seu desenvolvimento a partir do ponto em que houve a falha.

Nesse sentido a escola poderá auxiliá-las por meio de um acolhimento adequado, que permita às crianças sentirem-se contempladas e parte importante do ambiente escolar, uma vez que é justamente esse fator ambiental satisfatório que lhes faltaram.

As crianças, também, tendem a manifestar as tensões que sofreram em um ambiente sob a forma de um comportamento perturbado no outro. Quanto a isso, pais e professores podem auxiliar uns aos outros, para que compreendam as possíveis causas da manifestação agressiva e possam buscar formas de minimizá-las.

Outro aspecto que deve ser salientado é o fato de as crianças pequenas, de um modo geral, apresentarem dificuldades para lidar com suas emoções fortes e agressivas, por ainda não possuírem uma relação firme com a realidade externa e suas personalidades não estarem 
bem integradas, a ponto de ainda não lidarem bem com seus instintos, cabendo ao professor ajudá-las nessa difícil tarefa.

[...] a professora deve, por vezes, proteger as crianças delas próprias e exercer o controle e orientação necessários na situação imediata; e, além disso, assegurar o fornecimento de atividades lúdicas satisfatórias para ajudar a criança a guiar sua própria agressividade para canais construtivos e adquirir habilidades eficazes. (WINNICOTT, 1982, p.223)

A atividade lúdica no contexto escolar pode ser uma importante possibilidade de auxílio, pois, segundo Winnicott (1982), o brincar representa uma forma de comunicação através da qual a criança revela seus sentimentos, simboliza e elabora seus conflitos, permitindo que entre em contato com a sua realidade íntima psíquica pessoal, e, por isso, em suas atividades, poderemos encontrar expressões de amor e agressividade.

Winnicott (1982) acredita que ao manifestar seus impulsos destrutivos no brinquedo, a criança se sente confortada, pois, os sentimentos agressivos expressos não retornam do objeto para ela. Além do mais, o brinquedo permite que a criança transfira os sentimentos agressivos que possui em relação a alguém para um objeto, assim, ela descarrega seus impulsos coléricos sobre uma forma simbólica e substituível que atende suas necessidades.

Os brinquedos disponibilizados para a criança precisam ser resistentes, para que não se quebrem com facilidade, pois isto acarretaria frustração e angústias. Mas, se caso virem a quebrar, é indispensável que o adulto auxilie a criança no conserto, pois ela precisa exercer sua capacidade de reparação para que não se sinta culpada.

O professor precisa tolerar a agressividade durante a brincadeira, pois, caso contrário, sua intolerância acarretará frustrações e angústias na criança, e, dessa maneira, a finalidade de elaboração das angústias na brincadeira não será alcançada, ao invés disso, gerará mais angústias.

Nas brincadeiras, ainda, a criança encontra a possibilidade de elaborar seus conflitos e suas angústias, assumir papéis e vivenciar situações que não são permitidas na vida real. Esse conforto encontrado na atividade lúdica pode trazer impactos benéficos aos alunos cujas dificuldades emocionais estejam prejudicando sua atenção em sala de aula, seu adequado aprendizado e relacionamento com as demais crianças.

Portanto, acredita-se que o brincar pode ser um excelente aliado tanto para o professor - em sua tarefa de educar - quanto para as crianças nessa fase de suprema importância, na qual está se desenvolvendo mentalmente e formando a sua personalidade. 
Ao refletir-se acerca das possíveis contribuições que a instituição escolar pode prestar à criança que apresenta o comportamento agressivo, nota-se novamente a importância da formação do professor. O professor precisa de uma formação que o capacite para compreender e lidar com os aspectos afetivos e emocionais que permeiam o contexto escolar. Assim como Winnicott (1990) considera-se que conhecer o desenvolvimento emocional infantil não é algo apenas de interesse de teóricos e psicoterapeutas, visto que repercute diretamente no trabalho desempenhado pelo docente em sala de aula.

Tais afirmações não reivindicam uma atuação do professor como psicólogo, mas sim ressaltam que aspectos psicológicos e emocionais são inerentes e interferem no processo de ensino-aprendizagem, sendo fundamental ao professor conhecê-los para que possa auxiliar, dentro de suas possibilidades profissionais, as crianças que estejam em dificuldades.

$\mathrm{Na}$ ausência desse tipo de conhecimento, o professor poderá não identificar as possíveis causas de uma determinada manifestação agressiva e planejar sua atuação de forma consequente; poderá reagir frente à agressividade da criança também de forma agressiva; ser retaliativo frente a um gesto de reparação, por entendê-lo como cinismo; conceber a agressividade como uma perseguição pessoal ou não fornecer espaço para o brincar construtivo devido à falta de conhecimento sobre o seu valor.

Portanto, espera-se que o professor, de posse desse conhecimento, tenha um olhar mais sensível e atento para com os alunos que manifestam agressividade, pois acredita-se que constitui tarefa básica de todos os profissionais que atuam no espaço escolar, conscientizar-se do impacto de suas ações na formação integral do indivíduo e trabalhar de forma correspondente.

\section{CONCLUSÃO}

Discutiu-se, por meio deste trabalho, os fatores escolares que influenciam na agressividade em sala de aula, assim como as possibilidades de prevenção e de auxílio que a escola pode fornecer às crianças que apresentam tal conduta.

A partir da teoria winnicottiana e das reflexões proporcionadas por esta, percebeu-se a importância de os profissionais que atuam no espaço escolar conhecerem sobre o tema em epígrafe. Além disso, conclui-se que a instituição escolar pode auxiliar na amenização da conduta agressiva, por meio de ações que não extrapolam sua função ou capacidade, já que grande parte delas constituem papéis básicos da educação escolar no processo de formação do sujeito. 
Ao longo do trabalho, ressaltaram-se os impactos das ações a quem foi confiado o cuidado de crianças e a necessidade de se refletir sobre as formas de cuidado que estão sendo fornecidas a elas, na intenção de se prevenir e auxiliar crianças que, por motivos diversos, não estão conseguindo gerenciar a contento seus aspectos destrutivos.

Enfim, os conteúdos aqui abordados evidenciaram a necessidade de um olhar atento e sensível às manifestações infantis.

\section{REFERÊNCIAS}

LÜDKE, M.; ANDRÉ, M. E. D. A. Pesquisa em Educação: abordagens qualitativas. São Paulo: EPU, 1986.

WINNICOTT, D. W. A criança e o seu mundo. 6 ed. Rio de Janeiro: LTC- Livros Técnicos e Científicos Editora S.A., 1982.

. Natureza Humana. Rio de Janeiro: Imago Ed., 1990. 